\title{
Correction to: Celiac Disease Screening for High-Risk Groups: Are We Doing It Right?
}

\section{Dennis Kumral ${ }^{1} \cdot$ Sana Syed ${ }^{2}$}

Published online: 4 July 2020

(c) Springer Science+Business Media, LLC, part of Springer Nature 2020

\section{Correction to: Digestive Diseases and Sciences https://doi.org/10.1007/s10620-020-06352-w}

The original version of the article is unfortunately missing the funding information. Funding note is given below.

Funding Research reported in this publication was supported by National Institute of Diabetes and Digestive and Kidney Diseases (NIDDK) of the National Institutes of Health under award number K23DK117061-01A1 (SS).
Publisher's Note Springer Nature remains neutral with regard to jurisdictional claims in published maps and institutional affiliations.

The original article can be found online at https://doi.org/10.1007/ s10620-020-06352-w.

Dennis Kumral

dk3mb@virginia.edu

Sana Syed

sana.syed@virginia.edu

1 Department of Medicine, Division of Gastroenterology and Hepatology, University of Virginia, 1215 Lee Street, PO Box 800708, Charlottesville, VA 22908, USA

2 Department of Pediatrics, Division of Gastroenterology, Hepatology and Nutrition, School of Medicine, University of Virginia, MR-4 Bldg, 409 Lane Rd., Charlottesville, VA 22908, USA 